Article

\title{
Design of a Quick Switching Sampling System Based on the Coefficient of Variation
}

\author{
Ching-Ho Yen ${ }^{1}$, Muhammad Aslam ${ }^{2, *} \mathbb{D}$, Chia-Hao Chang ${ }^{3}$, Muhammad Zahir Khan ${ }^{4}(\mathbb{D})$ and \\ Chi-Hyuck Jun ${ }^{5}$ \\ 1 Department of Industrial Engineering \& Management Information, Huafan University, \\ New Taipei City 22301, Taiwan; jimyen@cc.hfu.edu.tw \\ 2 Department of Statistics, Faculty of Science, King Abdulaziz University, Jeddah 21551, Saudi Arabia \\ 3 Department of Nursing, Chang Gung University of Science and Technology, Chiayi Campus, \\ Chiayi 60004, Taiwan; howellchang@gmail.com \\ 4 Department of Mathematics and Statistics, Riphah International University, Islamabad 44000, Pakistan; \\ zerishkh@gmail.com \\ 5 Department of Industrial and Management Engineering, POSTECH, Pohang 37673, Korea; \\ chjun@postech.ac.kr \\ * Correspondence: magmuhammad@kau.edu.sa or aslam_ravian@hotmail.com; Tel.: +966-593-329-841
}

Received: 27 September 2018; Accepted: 29 October 2018; Published: 30 October 2018

\begin{abstract}
In this research, a quick switching sampling (QSS) system based on the coefficient of variation $(\mathrm{CV})$ is developed, which utilizes information from present and previous lots to make a decision about the submitted lot of product. The design parameters of the proposed plan are determined through a non-linear optimization solution. In addition, the performance of the proposed plan is compared with plans available in the literature in terms of sample size. Finally, one example is given to illustrate the proposed plan.
\end{abstract}

Keywords: quick switching system; coefficient of variation; risks; sample size; normal distribution

\section{Introduction}

A high quality of product is a main target of many companies. This target can be achieved only when inspection of the product, at every stage, is done carefully. Usually, 100\% inspection of the goods is not feasible because of the costs, time, destructive tests and so on. Therefore, an acceptance sampling plan is widely used for inspection of goods, including raw material, semi-product, final product and product shipment. An acceptance sampling plan aims to make the decision of accepting or rejecting a lot based on the information obtained for the sample. Acceptance sampling plans are intended to reduce inspection cost, risks associated with inspection, and time for tests of lot sentencing. Two types of sampling plans, called the attribute sampling plan and variable sampling plan, have been widely used in the industry for the inspection of products. The attribute sampling plan applies to cases where the data comes from the counting process, while variable sampling plans are designed for the measurement data and contain more information about the variable of the study than attribute sampling plans. As mentioned by Montgomery [1], variable sampling plans would require a smaller sample size compared to attribute sampling plans. The details of various acceptance sampling plans and their applications can be seen in references [2-6].

Several acceptance sampling plans, such as single plans, double sampling plans, repetitive sampling plans and quick switching sampling (QSS) systems, have been used in the industry for lot sentencing. Among them, a single sampling plan is widely used in the industry for the inspection of the submitted lot, due to easy implementation. In single sampling, the fate of the submitted lot 
of product is dependent on single sample information. The double sampling plan involves making a decision of accepting or rejecting one lot or taking a second sample in the first sample. If a second sample is taken, then the decision is made based on the combined information of two samples. The repetitive sampling plan is used when the decision of lot sentencing cannot be made on the first sample. The QSS system was first introduced by Dodge [7] and Romboski [8]. The QSS system is also known as the tightened-normal-tightened (TNT) sampling plan, originally proposed by Calvin [9]. Calvin [9] showed that the QSS system is more efficient than a single sampling plan. Soundararajan et al. [10] provided some useful tables for this type of sampling plan. Vijayaraghavan et al [11] proposed another modified QSS system. Muthuraj et al. [12] designed a variable TNT plan. More details about TNT sampling plans can be seen in references $[13,14]$.

In most cases, the evaluation of the quality characteristics of the product is based on either the mean or the standard deviation. Nevertheless, in specific scenarios, the practitioner may be interested in the relative variability compared with the mean, instead of the changes in the mean or the standard deviation. The coefficient of variation $(\mathrm{CV})$ considers the degree of the standard deviation relative to the mean, which is used as a measure of variability for circumstances where the standard deviation is proportional to the mean, or measurements are made in different units. As Castagliola et al. [15] mentions "some quality characteristics related to the physical properties of products usually have the standard deviation proportional to the mean". For such a case, the CV can be regarded as a suitable quality index to evaluate the stability of the product quality. In manufacturing industries, the CV has been widely used in many practical applications of quality control, such as reliability [16-18], control chart $[15,19,20]$ and acceptance sampling plan. [21-24]

By exploring the literature and utilizing the best of the authors' knowledge, the existing sampling plans based on CV include the single sampling plan [21,22], the multiple dependent state sampling plan [23] and the two-stage sampling plan [24]. The work on the design of the QSS system is not yet proposed. Also, the QSS system is more efficient than the conventional single sampling plan, which contains a normal plan and a tightened plan. In this paper, the research question is the design of a decision tool for lot sentencing when the stability of the product characteristic is of critical concern. The hypothesis is that the standard deviation of the product characteristic is proportional to the mean of the product characteristic. Therefore, we aim to provide the parameters of a quick switching sampling system based on CV to make a judgement of one lot, which can minimize the sample size while satisfying the corresponding risks and quality levels required by the vendor and the customer.

\section{QSS System Based on CV}

As we know, the mean and standard deviation are usually both measured in the same units, and they give information on the central location and spread of data, respectively. However, it may be more suitable to use CV instead of standard deviation if we want to make a comparison of the stability of data sets with different units or widely different means. The CV considers the spread of data relative to the central location, a dimensionless number, which is defined as

$$
C V=\frac{\sigma}{\mu}
$$

where $\mu$ is the mean, and $\sigma$ is the standard deviation. In fact, the parameter $C V$ is usually unknown, so we must use the sample statistic to estimate it. To estimate the $C V$, let us define the natural estimator

$$
\hat{C V}=\frac{S}{\bar{X}}
$$

where $\bar{X}$ is the sample mean, and $S$ is the sample standard deviation. Suppose that the data obeys the normal distribution with mean $\mu$ and standard deviation $\sigma$, Iglewicz et al. [25] showed that the statistic 
estimator $\sqrt{n} / \hat{C V}$ is distributed as $t_{n-1, \delta}$, where $t_{n-1, \delta}$ is a non-central $t$ distribution with $n-1$ degrees of freedom and non-central parameter $\delta=\sqrt{n} / C V$.

\section{The Proposed Methodology}

According to reference [24] "The QSS (Quick Switching sampling) system provides a flexible sampling procedure by switching decision rules between normal and tightened inspections. Users can accordingly utilize these two inspection policies for lot sentencing. If the quality characteristic of interest follows a normal distribution and has two-sided specification limits (LSL and USL)", then the proposed methodology is operated as follows [14]:

(1) Step 1: Begin with the normal inspection. Take a random sample of size from the lot and compute.

(2) Step 2: Accept the lot if and continue the normal inspection for the next lot, where is the critical acceptance value under the normal inspection. Otherwise, switch to the tightened inspection as in Step 3 for the next lot.

(3) Step 3: During the tightened inspection, take a random sample of size from the lot and compute.

(4) Step 4: Accept the lot if and switch to the normal inspection as in Step 1 for the next lot, where is the critical acceptance value under the tightened inspection and $k_{T}<k_{N}$ Otherwise, continue the tightened inspection as in Step 3 for the next lot.

According to references $[7,8]$, the Operating Characteristic (OC) function of the QSS can be expressed as

$$
P_{a}(p)=\frac{P_{T}(p)}{1-P_{N}(p)+P_{T}(p)}
$$

where $P_{N}(p)$ is the probability of accepting a lot under the normal inspection and $P_{T}(p)$ is the probability of accepting a lot under the tightened inspection. Therefore, the OC function of the proposed sampling plan based on $C V$ can be written as

$$
P_{a}(C V)=\frac{P_{T}(C V)}{1-P_{N}(C V)+P_{T}(C V)}
$$

and $P_{T}(C V)$ and $P_{N}(C V)$ can also be expressed as

$$
\begin{gathered}
P_{T}(C V)=P\left(\hat{C V}<k_{T}\right)=P\left(t_{n-1, \sqrt{n} / C V}>\sqrt{n} / k_{T}\right) \\
P_{N}(C V)=P\left(\hat{C V}<k_{N}\right)=P\left(t_{n-1, \sqrt{n} / C V}>\sqrt{n} / k_{N}\right)
\end{gathered}
$$

Usually, the plan parameters of sampling plans are determined using the producer's risk, consumer's risk, acceptable quality level (AQL) and limiting quality level (LQL) on the OC curve. Through these two designated points $\left(C V_{A Q L}, 1-\alpha\right)$ and $\left(C V_{L T P D}, \beta\right)$, the proposed sampling plan based on $C V$ can be obtained as

$\operatorname{Min} n$

$$
\begin{gathered}
\text { St. } P_{a}\left(C V_{A Q L}\right) \geq 1-\alpha \\
P_{a}\left(C V_{L T P D}\right) \leq \beta
\end{gathered}
$$

where $C V_{A Q L}$ and $C V_{L T P D}$ are the acceptable quality level and lot tolerance percent defective for $C V$, respectively.

Referring to Equations (4)-(6), the above model can be expressed as

St. 


$$
\begin{gathered}
P\left(C V_{A Q L}\right)=\frac{P\left(t_{n-1, \sqrt{n} / C V_{A Q L}}>\sqrt{n} / k_{T}\right)}{1-P\left(t_{n-1, \sqrt{n} / C V_{A Q L}}>\sqrt{n} / k_{N}\right)+P\left(t_{n-1, \sqrt{n} / C V_{A Q L}}>\sqrt{n} / k_{T}\right)} \geq 1-\alpha \\
P\left(C V_{L T P D}\right)=\frac{P\left(t_{n-1, \sqrt{n} / C V_{L T P D}}>\sqrt{n} / k_{T}\right)}{1-P\left(t_{n-1, \sqrt{n} / C V_{L T T P D}}>\sqrt{n} / k_{N}\right)+P\left(t_{n-1, \sqrt{n} / C V_{L T P D}}>\sqrt{n} / k_{T}\right)} \leq \beta k_{N}>k_{T}
\end{gathered}
$$

To apply the proposed plan in the industry, the plan parameters $n, k_{N}$ and $k_{T}$ are given for the sampling plans, with commonly used $\alpha, \beta, C V_{A Q L}$ and $C V_{L T P D}$. Tables $1-4$ display the values $\left(n, k_{T}\right.$, $\left.k_{N}\right)$ for the producer's $\alpha$-risk and buyer's $\beta$-risk, $(\alpha, \beta)=(0.05,0.1),(0.1,0.05),(0.05,0.05)$ and $(0.1,0.1)$, with some quality levels of the coefficient of variation.

Table 1. The parameters $\left(n, k_{T}, k_{N}\right)$ of the proposed sampling plan for $\alpha=0.05$ and $\beta=0.1$.

\begin{tabular}{ccccc}
\hline$C V_{A Q L}$ & $C V_{\text {LTPD }}$ & $\boldsymbol{n}$ & $\boldsymbol{k}_{\boldsymbol{T}}$ & $\boldsymbol{k}_{\boldsymbol{N}}$ \\
\hline 0.05 & 0.06 & 50 & 0.0501 & 0.0597 \\
& 0.07 & 14 & 0.0472 & 0.0695 \\
& 0.08 & 8 & 0.0449 & 0.0766 \\
& 0.09 & 6 & 0.0449 & 0.0806 \\
& 0.10 & 5 & 0.0448 & 0.0836 \\
\hline 0.06 & 0.07 & 69 & 0.0601 & 0.0699 \\
& 0.08 & 19 & 0.0576 & 0.0798 \\
& 0.09 & 10 & 0.0549 & 0.0883 \\
& 0.10 & 7 & 0.053 & 0.0945 \\
0.07 & 0.11 & 6 & 0.0519 & 0.0977 \\
& 0.08 & 92 & 0.0703 & 0.0799 \\
& 0.09 & 25 & 0.0684 & 0.0898 \\
& 0.10 & 13 & 0.0659 & 0.0984 \\
& 0.11 & 8 & 0.0611 & 0.1082 \\
0.08 & 0.12 & 7 & 0.0651 & 0.1089 \\
& 0.09 & 118 & 0.0804 & 0.0899 \\
& 0.10 & 32 & 0.079 & 0.0998 \\
& 0.11 & 16 & 0.0768 & 0.1088 \\
& 0.12 & 10 & 0.073 & 0.118 \\
& 0.13 & 8 & 0.0739 & 0.1219 \\
\hline 0.09 & 0.10 & 151 & 0.0906 & 0.0999 \\
& 0.11 & 40 & 0.0894 & 0.1098 \\
& 0.12 & 19 & 0.0866 & 0.1198 \\
& 0.13 & 14 & 0.0893 & 0.1236 \\
& 0.14 & 9 & 0.0819 & 0.1352 \\
\hline & & & &
\end{tabular}

Referring to the designed sampling system, the practitioners can determine the number of production items to be sampled and the corresponding critical values between normal and tightened inspections. For example, if the benchmarking quality level $\left(C V_{A Q L}, C V_{L T P D}\right)$ is set to $(0.07,0.09)$ with the producer's $\alpha$-risk $=0.05$, and the buyer's $\beta$-risk $=0.10$, then the corresponding sample size and critical values for a normal inspection and tightened inspection can be obtained as $\left(n, k_{N}\right)=(25,0.0898)$ and $\left(n, k_{T}\right)=(25,0.0684)$, respectively. 
Table 2. The parameters $\left(n, k_{T}, k_{N}\right)$ of the proposed sampling plan for $\alpha=0.1$ and $\beta=0.05$.

\begin{tabular}{ccccc}
\hline$C V_{\text {AQL }}$ & $\boldsymbol{C} V_{\text {LTPD }}$ & $\boldsymbol{n}$ & $\boldsymbol{k}_{\boldsymbol{T}}$ & $\boldsymbol{k}_{\boldsymbol{N}}$ \\
\hline 0.05 & 0.06 & 43 & 0.0471 & 0.0598 \\
& 0.07 & 13 & 0.0423 & 0.0691 \\
& 0.08 & 9 & 0.0432 & 0.0714 \\
& 0.09 & 7 & 0.0436 & 0.0735 \\
& 0.10 & 6 & 0.0448 & 0.0745 \\
\hline 0.06 & 0.07 & 60 & 0.0574 & 0.0698 \\
& 0.08 & 17 & 0.0522 & 0.0799 \\
& 0.09 & 11 & 0.0524 & 0.0834 \\
& 0.10 & 8 & 0.0513 & 0.0873 \\
0.07 & 0.11 & 7 & 0.0537 & 0.0875 \\
\hline 0.08 & 0.08 & 80 & 0.0674 & 0.0799 \\
& 0.09 & 23 & 0.0635 & 0.0892 \\
& 0.10 & 15 & 0.062 & 0.937 \\
& 0.11 & 10 & 0.0624 & 0.0977 \\
& 0.12 & 8 & 0.0624 & 0.1005 \\
\hline 0.09 & 0.09 & 103 & 0.0776 & 0.0899 \\
& 0.10 & 29 & 0.0738 & 0.0994 \\
& 0.11 & 16 & 0.071 & 0.1064 \\
& 0.12 & 12 & 0.0719 & 0.1091 \\
& 0.13 & 9 & 0.0706 & 0.1136 \\
\hline 0.10 & 129 & 0.0877 & 0.0999 \\
& 0.11 & 36 & 0.0842 & 0.1094 \\
& 0.12 & 19 & 0.0814 & 0.1169 \\
& 0.13 & 14 & 0.0825 & 0.1199 \\
& 0.14 & 11 & 0.0819 & 0.1235 \\
\hline
\end{tabular}

Table 3. The parameters $\left(n, k_{T}, k_{N}\right)$ of the proposed sampling plan for $\alpha=0.05$ and $\beta=0.05$.

\begin{tabular}{ccccc}
\hline$C V_{A Q L}$ & $C V_{\text {LTPD }}$ & $\boldsymbol{n}$ & $\boldsymbol{k}_{\boldsymbol{T}}$ & $\boldsymbol{k}_{\boldsymbol{N}}$ \\
\hline 0.05 & 0.06 & 54 & 0.0486 & 0.0599 \\
& 0.07 & 16 & 0.0451 & 0.0693 \\
& 0.08 & 9 & 0.042 & 0.0766 \\
& 0.09 & 7 & 0.0423 & 0.0796 \\
& 0.10 & 6 & 0.0436 & 0.0812 \\
\hline 0.06 & 0.07 & 76 & 0.0588 & 0.0699 \\
& 0.08 & 22 & 0.059 & 0.0792 \\
& 0.09 & 12 & 0.0534 & 0.0867 \\
& 0.10 & 9 & 0.0537 & 0.0903 \\
0.07 & 0.11 & 7 & 0.0524 & 0.0948 \\
& 0.08 & 103 & 0.0689 & 0.0799 \\
& 0.09 & 29 & 0.0664 & 0.0893 \\
& 0.10 & 15 & 0.0636 & 0.0976 \\
& 0.11 & 10 & 0.0607 & 0.1047 \\
0.08 & 0.12 & 8 & 0.0607 & 0.1084 \\
\hline 0.09 & 0.09 & 132 & 0.0791 & 0.0899 \\
& 0.10 & 36 & 0.0765 & 0.0997 \\
& 0.11 & 18 & 0.0731 & 0.1089 \\
& 0.12 & 12 & 0.0709 & 0.1159 \\
& 0.13 & 10 & 0.0732 & 0.1179 \\
\hline \multirow{2}{*}{0.10} & 167 & 0.0892 & 0.0999 \\
& 0.11 & 46 & 0.0873 & 0.1093 \\
& 0.12 & 22 & 0.0837 & 0.1191 \\
& 0.13 & 14 & 0.0806 & 0.1274 \\
& 0.14 & 11 & 0.0809 & 0.1316 \\
\hline & & & &
\end{tabular}


Table 4. The parameters $\left(n, k_{T}, k_{N}\right)$ of the proposed sampling plan for $\alpha=0.1$ and $\beta=0.1$.

\begin{tabular}{ccccc}
\hline$C V_{A Q L}$ & $C V_{\text {LTPD }}$ & $\boldsymbol{n}$ & $\boldsymbol{k}_{\boldsymbol{T}}$ & $\boldsymbol{k}_{\boldsymbol{N}}$ \\
\hline 0.05 & 0.06 & 37 & 0.0484 & 0.0598 \\
& 0.07 & 11 & 0.044 & 0.0693 \\
& 0.08 & 7 & 0.0431 & 0.0738 \\
& 0.09 & 6 & 0.0469 & 0.0735 \\
& 0.10 & 5 & 0.047 & 0.0756 \\
\hline 0.06 & 0.07 & 52 & 0.0586 & 0.0698 \\
& 0.08 & 15 & 0.0549 & 0.0794 \\
& 0.09 & 9 & 0.0529 & 0.0851 \\
& 0.10 & 7 & 0.0554 & 0.0867 \\
0.07 & 0.11 & 6 & 0.0578 & 0.0876 \\
\hline 0.08 & 0.08 & 69 & 0.0687 & 0.799 \\
& 0.09 & 19 & 0.065 & 0.0899 \\
& 0.10 & 11 & 0.0638 & 0.0959 \\
& 0.11 & 8 & 0.063 & 0.1002 \\
& 0.12 & 6 & 0.0605 & 0.1056 \\
\hline 0.09 & 0.09 & 90 & 0.0789 & 0.0899 \\
& 0.10 & 25 & 0.0762 & 0.0994 \\
& 0.11 & 13 & 0.0731 & 0.1075 \\
& 0.12 & 9 & 0.0718 & 0.113 \\
& 0.13 & 7 & 0.0706 & 0.1174 \\
\hline 0.10 & 113 & 0.089 & 0.0999 \\
& 0.11 & 31 & 0.0866 & 0.1094 \\
& 0.12 & 16 & 0.0842 & 0.1174 \\
& 0.13 & 11 & 0.0835 & 0.1227 \\
& 0.14 & 8 & 0.0803 & 0.1294 \\
\hline
\end{tabular}

\section{Comparison and Analysis}

A sampling plan can be regarded as better if it requires a lower sample size compared to other sampling plans with the same protection to the buyer and the vendor. In addition, owing to the existence of sampling error in acceptance sampling plans, the risk of misjudging is unavoidable. Therefore, a well-designed sampling plan should have a high probability of accepting the lot at the acceptable quality level and a low probability of accepting the lot at lot tolerance percent defective, as well as a smaller sample size (average sample number).

In this section, two measures of the OC curve and sample size are used to evaluate the performance of the proposed method and two other sampling plans which are the single sampling plan based on CV [21] and the two-stage sampling plan based on CV [24].

The OC curve is extensively used to show the discriminatory power of sampling plans. Figures 1 and 2 display the OC curves for producer risk and buyer risk, $(\alpha, \beta)=(0.05,0.1)$ and $(0.1,0.05)$, respectively, which plot the probability of accepting a lot versus the various quality levels of the coefficient of variation. Overall, the appearance of the OC curve for our proposed methodology is closer to the ideal OC curve. As shown in Figures $1 b-d$ and $2 b-d$, we can observe that the slopes of the OC curves for our proposed methodology are steeper than those of the two other sampling plans. On the other hand, the average sample numbers for three sampling plans gives the combination of producer risk and buyer risk, $(\alpha, \beta)=(0.05,0.1)$ and $(0.1,0.05)$, displayed in Table 5. From Table 5, we can observe the sample size of the proposed plan is significantly smaller than those of the two other sampling plans for all combinations of quality levels. For example, when $C V_{A Q L}=0.06, C V_{L T P D}$ $=0.08, \alpha=0.05$ and $\beta=0.1$, the required average sample number of the proposed plan is only 19 . Instead, the required average sample numbers for Tong and Chen [21] and Yan et al. [24] are 53 and 47.1, respectively. So from the viewpoint of the OC curve and sample size, we can conclude that the proposed plan surely has a better performance than the existing plans based on CV. 
Table 5. Sample size for three plans.

\begin{tabular}{|c|c|c|c|c|c|c|c|}
\hline \multicolumn{2}{|c|}{ Quality Level } & \multicolumn{3}{|c|}{$\alpha=0.05, \beta=0.1$} & \multicolumn{3}{|c|}{$\alpha=0.1, \beta=0.05$} \\
\hline \multirow{2}{*}{\multicolumn{2}{|c|}{$C V_{A Q L} C V_{L T P D}$}} & Single & Two Stage & The Proposed & Single & Two Stage & The Proposed \\
\hline & & $n$ & $A S N$ & $n$ & $n$ & $A S N$ & $n$ \\
\hline \multirow[t]{5}{*}{0.05} & 0.06 & 131 & 104.34 & 50 & 134 & 106.65 & 43 \\
\hline & 0.07 & 39 & 32.35 & 14 & 41 & 35.64 & 13 \\
\hline & 0.08 & 20 & 17.42 & 8 & 23 & 19.71 & 9 \\
\hline & 0.09 & 14 & 12.32 & 6 & 15 & 13.15 & 7 \\
\hline & 0.10 & 11 & 8.78 & 5 & 12 & 10.14 & 6 \\
\hline \multirow[t]{5}{*}{0.06} & 0.07 & 182 & 149.3 & 69 & 186 & 160 & 60 \\
\hline & 0.08 & 53 & 47.10 & 19 & 56 & 47.41 & 17 \\
\hline & 0.09 & 28 & 22.88 & 10 & 28 & 26.23 & 11 \\
\hline & 0.10 & 17 & 15.03 & 7 & 20 & 16.70 & 8 \\
\hline & 0.11 & 14 & 11.30 & 6 & 15 & 11.87 & 7 \\
\hline \multirow[t]{5}{*}{0.07} & 0.08 & 242 & 201.85 & 92 & 248 & 208.45 & 80 \\
\hline & 0.09 & 69 & 57.36 & 25 & 72 & 62.22 & 23 \\
\hline & 0.10 & 35 & 28.41 & 13 & 36 & 33.61 & 15 \\
\hline & 0.11 & 23 & 19.71 & 8 & 25 & 20.74 & 10 \\
\hline & 0.12 & 17 & 14.04 & 7 & 17 & 15.23 & 8 \\
\hline \multirow[t]{4}{*}{0.08} & 0.09 & 311 & 271.33 & 118 & 318 & 256.93 & 103 \\
\hline & 0.10 & 88 & 71.48 & 32 & 91 & 76.48 & 29 \\
\hline & 0.11 & 44 & 38.55 & 16 & 46 & 39.42 & 16 \\
\hline & 0.12 & 28 & 23.28 & 10 & 30 & 24.65 & 12 \\
\hline \multirow[t]{3}{*}{0.09} & 0.10 & 327 & 317.43 & 151 & 336 & 324.45 & 129 \\
\hline & 0.11 & 109 & 92.62 & 40 & 112 & 93.51 & 36 \\
\hline & 0.12 & 55 & 43.41 & 19 & 56 & 48.63 & 19 \\
\hline
\end{tabular}

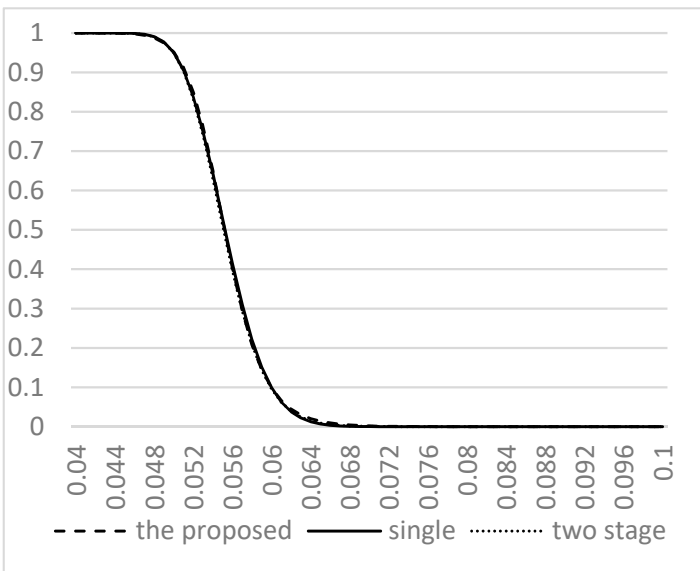

(a)

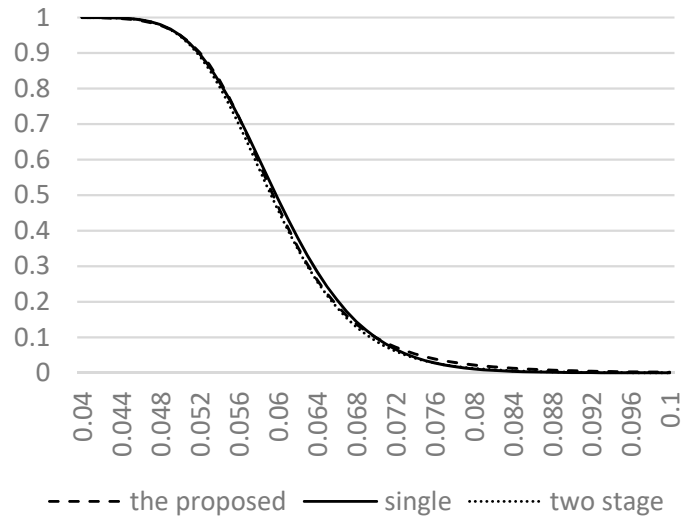

(b)

Figure 1. Cont. 


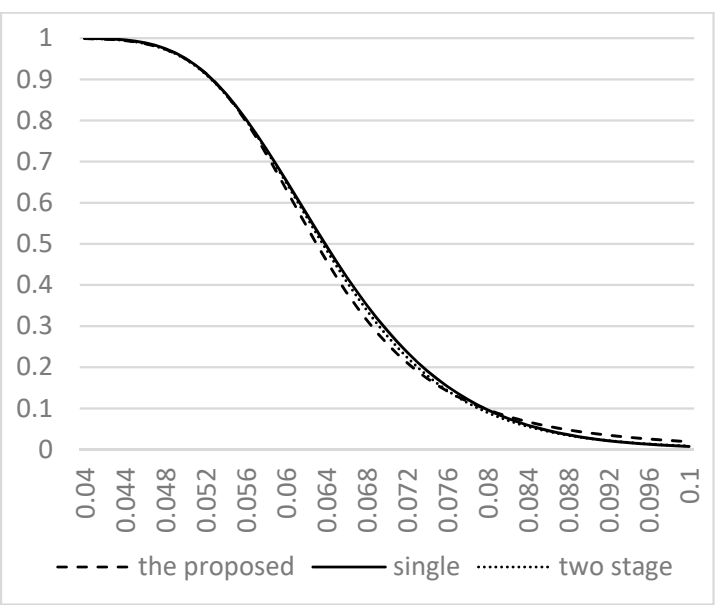

(c)

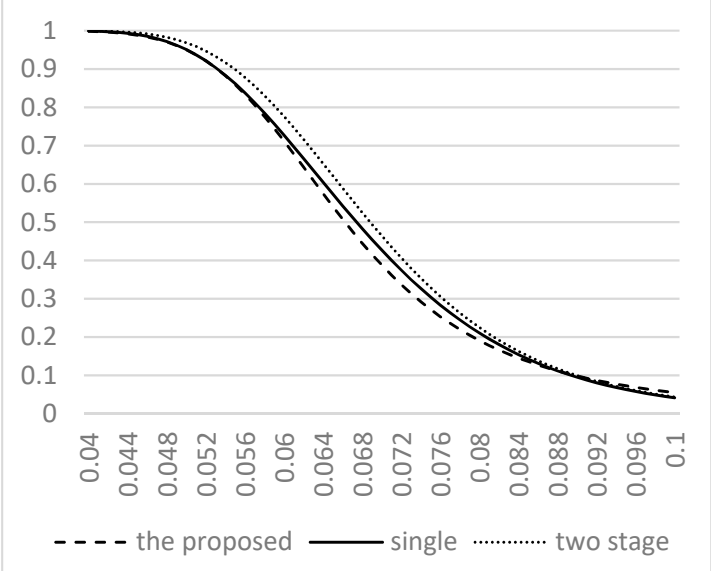

(d)

Figure 1. The OC curves for three plans with quality levels under $\alpha=0.05, \beta=0.1$. (a) The OC curves for three plans with quality level, $C V_{A Q L}=0.05, C V_{L T P D}=0.06$; (b) The OC curves for three plans with quality level, $C V_{A Q L}=0.05, C V_{L T P D}=0.07$; (c) The OC curves for three plans with quality level, $C V_{A Q L}=0.05, C V_{L T P D}=0.08$; (d) The OC curves for three plans with quality level, $C V_{A Q L}=0.05$, $C V_{L T P D}=0.09$.

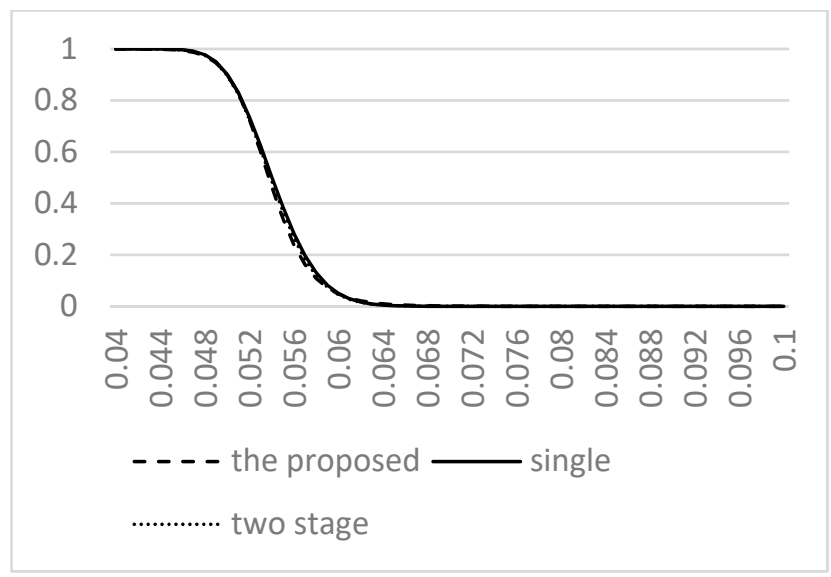

(a)

Figure 2. Cont. 


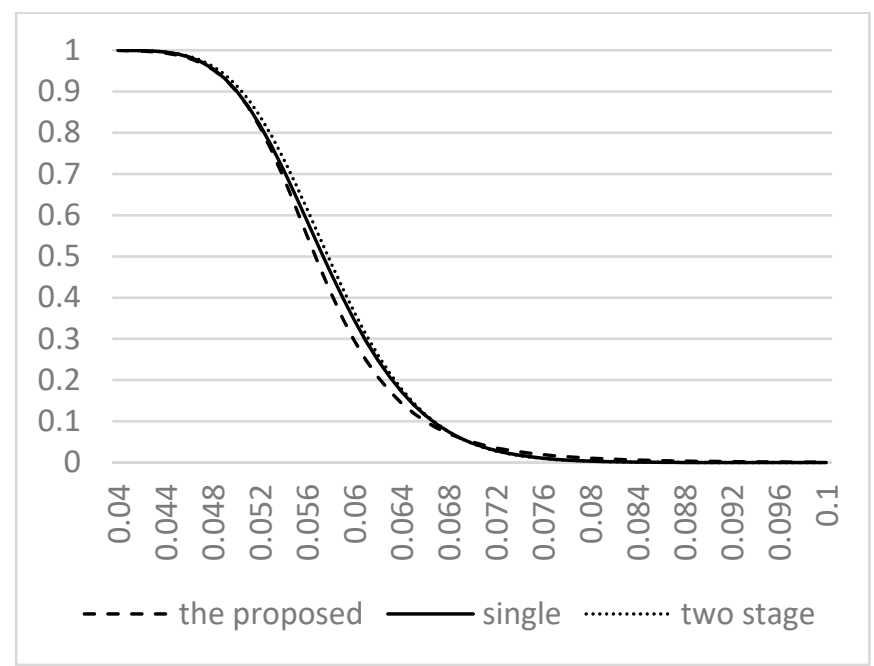

(b)

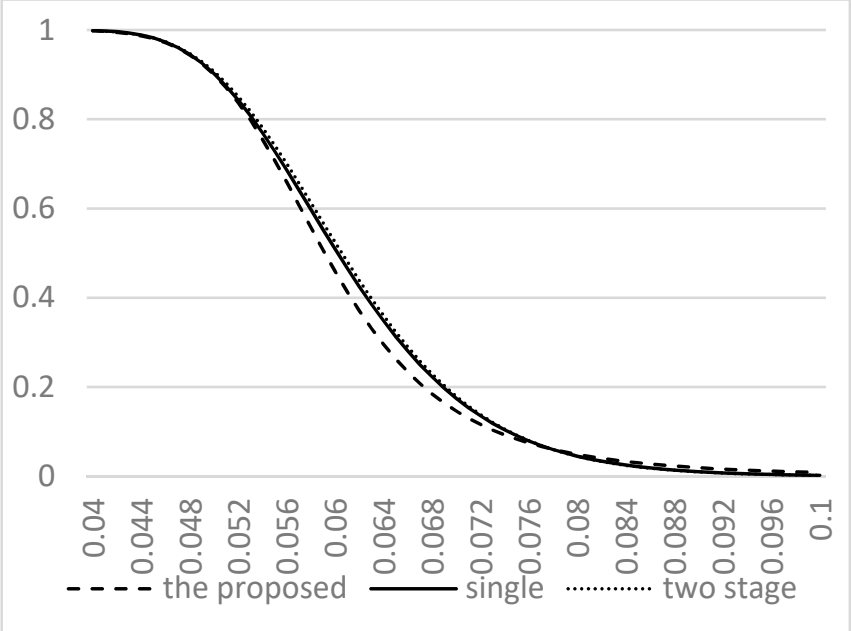

(c)

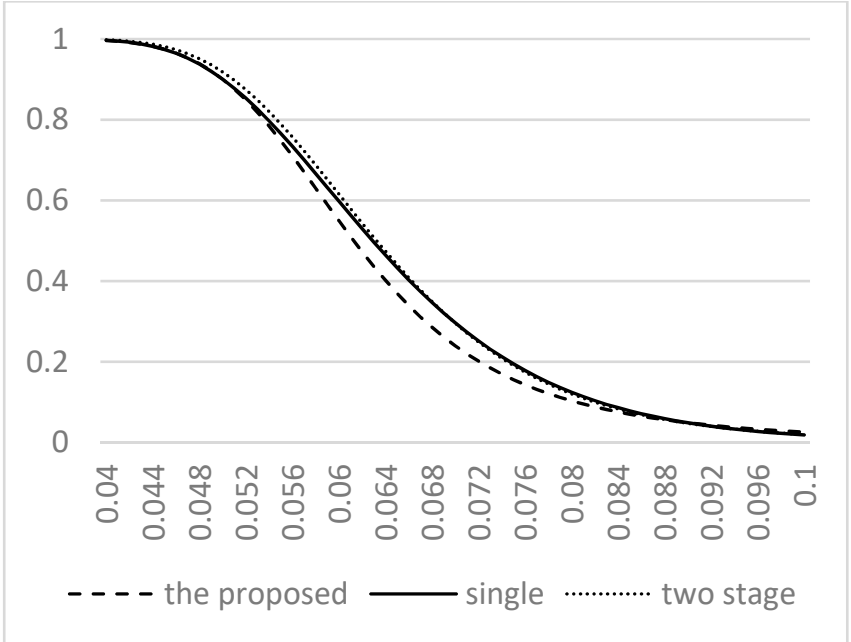

(d)

Figure 2. The Operating Characteristic (OC) curves for three plans with quality levels under $\alpha=0.1$, $\beta=0.05$. (a) The OC curves for three plans with quality level, $C V_{A Q L}=0.05, C V_{L T P D}=0.06$; (b) The OC curves for three plans with quality level, $C V_{A Q L}=0.05, C V_{L T P D}=0.07$; (c) The OC curves for three plans with quality level, $C V_{A Q L}=0.05, C V_{L T P D}=0.08$; (d) The OC curves for three plans with quality level, $C V_{A Q L}=0.05, C V_{L T P D}=0.09$. 
In order to confirm the performance of the proposed method and two stage sampling plan, we simulate $\mathrm{N}=10000$ lots in each combination of Table 6, to calculate the probability of accepting or rejecting lots and the corresponding ASN (Average Sample Number). The outputs of this simulation are displayed in Table 7 . The simulation results clearly indicate that the probabilities of accepting lots are all very close to the predetermined value of $1-\alpha$ and $\beta$ in all the cases we investigated. Furthermore, we also see the ASN of the proposed method is obviously smaller than that of two-stage sampling plan for all combinations of quality levels. Thus, we can conclude that the proposed method provides a smaller ASN than that of the two-stage sampling plan.

Table 6. The parameters of two sampling plans for $\alpha=0.05$ and $\beta=0.1$.

\begin{tabular}{ccccccccc}
\hline \multicolumn{2}{c}{ Quality Level } & \multicolumn{3}{c}{ The Proposed Method } & \multicolumn{3}{c}{ Two Stage Sampling } \\
\hline $\mathbf{C V}_{\text {AQL }}$ & $\mathbf{C V}_{\text {LTPD }}$ & $\boldsymbol{n}$ & $\boldsymbol{k}_{\boldsymbol{T}}$ & $\boldsymbol{k}_{\boldsymbol{N}}$ & $\boldsymbol{n}_{\mathbf{1}}=\boldsymbol{n}_{\mathbf{2}}=\boldsymbol{n}$ & $\boldsymbol{k}_{\boldsymbol{a} \mathbf{1}}$ & $\boldsymbol{k}_{\boldsymbol{a} \mathbf{2}}$ & $\boldsymbol{k}_{\boldsymbol{r}}$ \\
\hline & 0.06 & 50 & 0.0501 & 0.0597 & 90 & 0.0535 & 0.0540 & 0.0569 \\
0.05 & 0.07 & 14 & 0.0472 & 0.0695 & 28 & 0.0558 & 0.0570 & 0.0625 \\
& 0.08 & 8 & 0.0449 & 0.0766 & 15 & 0.0561 & 0.0658 & 0.0658 \\
& 0.09 & 6 & 0.0449 & 0.0806 & 10 & 0.0556 & 0.0703 & 0.0735 \\
& 0.10 & 5 & 0.0448 & 0.0836 & 7 & 0.0533 & 0.0723 & 0.0751 \\
\hline
\end{tabular}

Table 7. Probabilities of accepting the lot with various $\left(\mathrm{CV}_{\mathrm{AQL}}, \mathrm{CV}_{\mathrm{LTPD}}\right)$ for $\alpha=0.05$ and $\beta=0.10$ by simulation with 10000 times.

\begin{tabular}{|c|c|c|c|c|c|c|c|c|c|c|c|c|c|}
\hline \multicolumn{14}{|c|}{ The Proposed Method } \\
\hline \multicolumn{2}{|c|}{ Quality Level } & \multicolumn{6}{|c|}{$\begin{array}{l}\text { The Probability of Acceptance or Rejection } \\
\text { under } \mathrm{CV}_{\mathrm{AQL}}\end{array}$} & \multicolumn{6}{|c|}{$\begin{array}{l}\text { The Probability of Acceptance or Rejection } \\
\text { under } C_{\text {LTPD }}\end{array}$} \\
\hline $\mathrm{CV}_{\mathrm{AQL}}$ & $\mathrm{CV}_{\text {LTPD }}$ & NA & NR & TA & TR & AP & ASN & NA & NR & TA & TR & LP & ASN \\
\hline \multirow{5}{*}{0.05} & 0.06 & 0.9188 & 0.0289 & 0.0289 & 0.0234 & 0.9477 & 50.00 & 0.0484 & 0.0477 & 0.0476 & 0.8563 & 0.096 & 50.00 \\
\hline & 0.07 & 0.9263 & 0.0215 & 0.0215 & 0.0307 & 0.9478 & 14.00 & 0.0544 & 0.0444 & 0.0443 & 0.8569 & 0.0987 & 14.00 \\
\hline & 0.08 & 0.9305 & 0.0213 & 0.0213 & 0.0269 & 0.9518 & 8.00 & 0.0532 & 0.0502 & 0.0501 & 0.8465 & 0.1033 & 8.00 \\
\hline & 0.09 & 0.9257 & 0.0223 & 0.0223 & 0.0297 & 0.948 & 6.00 & 0.0483 & 0.0557 & 0.0557 & 0.8403 & 0.104 & 6.00 \\
\hline & 0.10 & 0.9273 & 0.0235 & 0.0235 & 0.0257 & 0.9508 & 5.00 & 0.0421 & 0.0595 & 0.0594 & 0.839 & 0.1015 & 5.00 \\
\hline \multicolumn{14}{|c|}{ Two Stage Sampling Plan } \\
\hline \multicolumn{2}{|c|}{ Quality Level } & \multicolumn{6}{|c|}{$\begin{array}{l}\text { The Probability of Acceptance or Rejection } \\
\text { under } C_{A Q L}\end{array}$} & \multicolumn{6}{|c|}{$\begin{array}{l}\text { The Probability of Acceptance or Rejection } \\
\text { under } C_{\text {LTPD }}\end{array}$} \\
\hline $\mathrm{CV}_{\mathrm{AQL}}$ & CV $_{\text {LTPD }}$ & FA & FR & SA & SR & AP & ASN & FA & FR & SA & SR & LP & ASN \\
\hline \multirow{5}{*}{0.05} & 0.06 & 0.8351 & 0.0359 & 0.1034 & 0.0256 & 0.9385 & 101.61 & 0.0733 & 0.7401 & 0.0093 & 0.1773 & 0.0826 & 106.79 \\
\hline & 0.07 & 0.8226 & 0.0365 & 0.1125 & 0.0284 & 0.9351 & 31.95 & 0.0708 & 0.7534 & 0.0088 & 0.167 & 0.0796 & 32.92 \\
\hline & 0.08 & 0.7833 & 0.0463 & 0.1675 & 0.0029 & 0.9508 & 17.56 & 0.0642 & 0.7995 & 0.037 & 0.0993 & 0.1012 & 17.04 \\
\hline & 0.09 & 0.7247 & 0.0225 & 0.2489 & 0.0039 & 0.9736 & 12.53 & 0.0597 & 0.7339 & 0.0604 & 0.146 & 0.1201 & 12.06 \\
\hline & 0.10 & 0.6609 & 0.0372 & 0.2963 & 0.0056 & 0.9572 & 9.11 & 0.0546 & 0.758 & 0.0554 & 0.132 & 0.11 & 8.31 \\
\hline
\end{tabular}

NA: the probability of lot acceptance at normal inspection; NR: the probability of lot rejection at normal inspection; TA: the probability of lot acceptance at tightened inspection; TR: the probability of lot rejection at tightened inspection; AP: the probability of lot acceptance under $\mathrm{CV}_{\mathrm{AQ}}$; LP: the probability of lot acceptance under $\mathrm{CV}_{\mathrm{LTPD}}$; FA: the probability of lot acceptance at first stage inspection; FR: the probability of lot rejection at first stage inspection; SA: the probability of lot acceptance at second stage inspection; SR: the probability of lot rejection at second stage inspection.

\section{An Example in Industry}

To demonstrate the applicability of the proposed methodology, an example of steel is used for illustration. Steel is an alloy of iron and other elements, and is widely used in construction and other applications because of its high tensile strength. So the tensile strength of steel is a critical characteristic. As mentioned by Wang and Xiao, [22] and Yan et al. [24], "In a steel factory, the mean tensile strength of each batch of steel may be different because of different techniques and a different proportion of ingredients or other factors. Frequently steel users are more concerned with the stability of tensile strength for one batch of steel than the average tensile strength for one batch of steel since the stability of tensile strength is very important for the enterprises who use the steel in batches to complete 
remanufacturing production". Therefore, when we want to judge if the stability of product quality meets the required quality level, a QSS based on CV can be implemented.

Suppose the specification limits of ultimate tensile strength for a particular model of A36 steel are $\mathrm{LSL}=400 \mathrm{MPa}$ and USL $=550 \mathrm{MPa}$. In the contract approved by both the vendor and the buyer, the quality level of $C V_{A Q L}$ and $C V_{L T P D}$ are set to 0.06 and 0.08 with $\alpha=0.05$ and $\beta=0.10$. Beginning with the normal inspection, we can find the inspected sample size and the corresponding critical acceptance value of the sampling system are $\left(n, k_{T}, k_{N}\right)=(19,0.0576,0.0798)$ from Table 1 . Sample data taken from the lot randomly are displayed in Table 8 . We use the normal probability plot to execute the normality test of sample data as shown in Figure 3, which indicates the sample data follow the normal distribution. Based on these observations, we can obtain

$$
\bar{X}=508.9758, S=32.23883, \text { and } \hat{C V}=\frac{S}{\bar{X}}=\frac{32.23883}{508.9758}=0.063341 .
$$

Since the value of $\hat{C V}$ is less than 0.0798 , this lot is accepted and we will continue the normal inspection for the next lot.

Table 8. The example data for tensile strength of A36 steel.

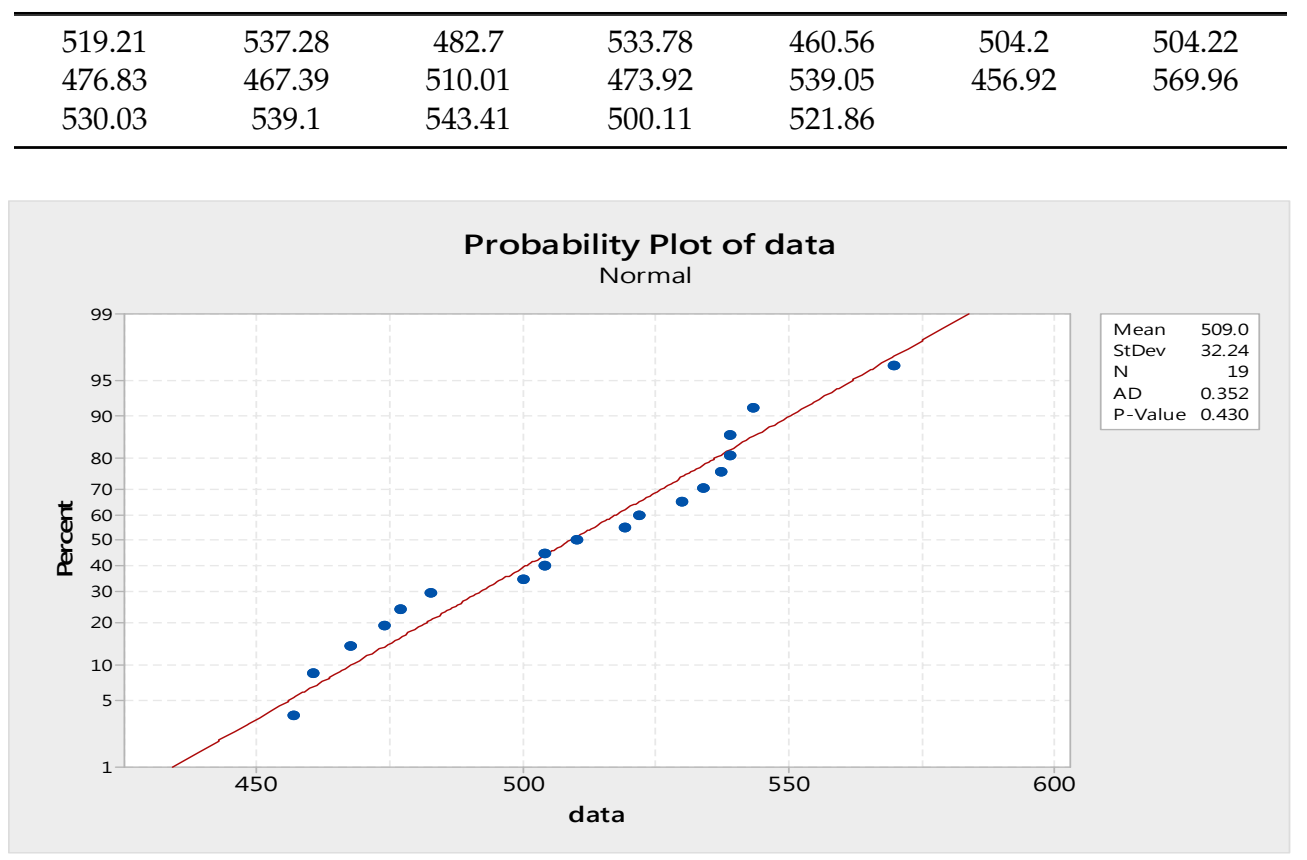

Figure 3. The normal probability plot for the sample data of steel.

\section{Conclusions}

The coefficient of variation, defined as the ratio of the standard deviation to the mean, is widely used to measure the relative variation of a variable to its mean in many practical applications. Especially, using this index to evaluate the performance of products is more suitable than other indices when the stability of product quality becomes a focus. In this paper, a QSS system based on CV is proposed for lot sentencing, which consists of a normal inspection and a tightened inspection. For practical purposes, we tabulate the sample size and critical values of the sampling system for some combinations of quality levels with specified risks. In addition, we implement the comparative analysis of the proposed method and two other sampling plans based on $\mathrm{CV}$, in terms of the required sample size and $\mathrm{OC}$ curve, which shows that our approach has a better performance than two others. In the end, an example is taken to illustrate the proposed methodology. The proposed methodology can be extended to build a new plan with rectifying inspection considerations for future research. 
Author Contributions: Conceived and designed the experiments, C.H.Y., M.A., C.H.C., M.Z.K. and C.H.J.; Performed the experiments, C.H.Y., M.A., C.H.C.; Contributed reagents/materials/analysis tools, C.H.Y., M.A., C.H.C., M.Z.K. and C.H.J.; Wrote the paper, C.H.Y., M.A., C.H.C. and C.H.J.

Funding: This work was supported by the Deanship of Scientific Research (DSR), King Abdulaziz University, Jeddah The author, Muhammad Aslam, therefore, acknowledge with thanks DSR technical support.

Acknowledgments: The authors are deeply thankful to the editor and the reviewers for their valuable suggestions to improve the quality of this manuscript.

Conflicts of Interest: The authors declare no conflict of interest.

\section{References}

1. Montgomery, D.C. Introduction to Statistical Quality Control; John Wiley \& Sons: Hoboken, NJ, USA, 2007.

2. Balamurali, S.; Jun, C. Repetitive group sampling procedure for variables inspection. J. Appl. Stat. 2006, 33, 327-338. [CrossRef]

3. Wu, C.-W.; Pearn, W.L. A variables sampling plan based on Cpmk for product acceptance determination. Eur. J. Oper. Res. 2008, 184, 549-560. [CrossRef]

4. Yen, C.-H.; Aslam, M.; Jun, C.-H. A lot inspection sampling plan based on EWMA yield index. Int. J. Adv. Manuf. Technol. 2014, 75, 861-868. [CrossRef]

5. Kurniati, N.; Yeh, R.-H.; Wu, C.-W. A sampling scheme for resubmitted lots based on one-sided capability indices. Qual. Technol. Quant. Manag. 2015, 12, 501-515. [CrossRef]

6. Aslam, M.; Azam, M.; Jun, C.-H. Acceptance sampling plans for multi-stage process based on time-truncated test for weibull distribution. Int. J. Adv. Manuf. Technol. 2015, 79, 1779-1785. [CrossRef]

7. Dodge, H.F. A New Dual System of Acceptance Sampling; The Statistics Center, Technical Report No. 16; The Statistics Center, Rutgers-The State University: New Brunswick, NJ, USA, 1967.

8. Romboski, L.D. An Investigation of Quick Switching Acceptance Sampling System. Ph.D. Thesis, Rutgers-The State University, New Jersey, NJ, USA, 1969.

9. Calvin, T.W. TNT Zero Acceptance Number Sampling. Available online: http://asq.org/qic/display-item/ index.html?item=1973 (accessed on 28 October 2018).

10. Soundararajan, V.; Vijayaraghavan, R. Construction and selection of tightened-normal-tightened sampling inspection scheme of type TNT-(n1, n2; c). J. Appl. Stat. 1992, 19, 339-349. [CrossRef]

11. Vijayaraghavan, R.; Soundararajan, V. Procedures and tables for the selection of tightened-normal-tightened (TNT-(n; c 1, c 2)) sampling schemes. J. Appl. Stat. 1996, 23, 69-80. [CrossRef]

12. Muthuraj, D.; Senthilkumar, D. Designing and construction of tightened-normal-tightened variables sampling scheme. J. Appl. Stat. 2006, 33, 101-111. [CrossRef]

13. Senthilkumar, D.; Muthuraj, D. Construction and selection of tightened-normal-tightened variables sampling scheme of type TNTVSS ( $\left.\mathrm{n}_{1}, \mathrm{n}_{2} ; \mathrm{k}\right)$. J. Appl. Stat. 2010, 37, 375-390. [CrossRef]

14. Aslam, M.; Balamurali, S.; Jun, C.-H.; Ahmad, M. A two-plan sampling system for life testing under weibull distribution. Ind. Eng. Manag. Syst. 2010, 9, 54-59. [CrossRef]

15. Castagliola, P.; Amdouni, A.; Taleb, H.; Celano, G. One-sided shewhart-type charts for monitoring the coefficient of variation in short production runs. Qual. Technol. Quant. Manag. 2015, 12, 53-67. [CrossRef]

16. Gomez, K.A.; Gomez, K.A.; Gomez, A.A. Statistical Procedures for Agricultural Research; John Wiley and Sons: Hoboken, NJ, USA, 1984.

17. Steel, R.G.D.; Torrie, J.H. Principles and Procedures of Statistics: A Biometrical Approach, 2nd ed.; McGraw-Hill: New York, NY, USA, 1980.

18. Taye, G.; Njuho, P. Monitoring field variability using confidence interval for coefficient of variation. Commun. Stat. Theory Methods 2008, 37, 831-846. [CrossRef]

19. Kang, C.W.; Lee, M.S.; Seong, Y.J. A Control Chart for the Coefficient of Variation. J. Qual. Technol. 2007, 39, 151-158. [CrossRef]

20. Calzada, M.E.; Scariano, S.M. A synthetic control chart for the coefficient of variation. J. Stat. Comput. Simul. 2013, 83, 853-867. [CrossRef]

21. Tong, Y.; Chen, Q. Sampling inspection by variables for coefficient of variation. Math. Theory Appl. Probab. 1991, 3, 315-327. 
22. Wang, J.Q.; Xiao, H.G. A variable single sampling inspection using the coefficient of variation as the quality index. J. Quant. Tech. Econ. 2001, 3, 117-119.

23. Yan, A.; Liu, S.; Dong, X. Designing a multiple dependent state sampling plan based on the coefficient of variation. SpringerPlus 2016, 5, 1447. [CrossRef] [PubMed]

24. Yan, A.; Liu, S.; Dong, X. Variables two stage sampling plans based on the coefficient of variation. J. Adv. Mech. Des. Syst. 2016, 10. [CrossRef]

25. Iglewicz, B.; Myers, R.; Howe, R. On the percentage points of the sample coefficient of variation. Biometrika 1968, 55, 580-581. [CrossRef]

(C) 2018 by the authors. Licensee MDPI, Basel, Switzerland. This article is an open access article distributed under the terms and conditions of the Creative Commons Attribution (CC BY) license (http://creativecommons.org/licenses/by/4.0/). 